\title{
Transformation of Kasuti Embroidery Motifs for Hand Painting
}

\author{
Renu*, Nisha Arya, N. Chauhan and Suman Sodhi \\ Department of Textile and Apparel Designing, I.C. College of Home Science, CCSHAU, \\ Hisar, Haryana, India \\ *Corresponding author
}

\begin{tabular}{|l|}
\hline Ke y w o r d s \\
$\begin{array}{l}\text { Kasuti, Embroidery, } \\
\text { Adaptation, Designs }\end{array}$ \\
\hline Article Info \\
\hline $\begin{array}{l}\text { Accepted: } \\
10 \text { March } 2018 \\
\text { Available Online: } \\
10 \text { April } 2018\end{array}$ \\
\hline
\end{tabular}

\section{Introduction}

India is a land of rich culture and diverse traditions. Its long-known heritage of art, music, dance, sculpture, architecture, carpentry, metal work, designing, painting and embroidery exemplifies the richness of Indian culture (Pandit, 1976). Among these, Indian embroidery profoundly expresses the richness of diversity because the art of embroidery is exhibited by Indians who have been living widely region wise India has a rich heritage of embroideries and people are well versed with
Embroidery is one of oldest and beautiful way of surface ornamentation. However, the revival of traditional kasuti embroidery needs to be twinned with ways to find new and contemporary expression in harmony with the needs and aspirations of future citizens of the world, while valuing the traditional. There is also a need to enhance understanding and to provide necessary support for professional marketing and adaptation to global demands as the craft moves into the new era. Therefore, the present study on transformation of kasuti embroidery motifs as hand painted articles was conducted for exploring the ossibility to enhance creativity by adapting traditional kasuti embroidery motifs for hand each for jacket for further application using hand painting technique. Developed articles were highly acceptable by respondents in terms of created designs, design placements, colour ways, technique, overall appearance and cost. Respondents had high opinion about developed articles. It was found that transformation of innovative designs of kasuti embroidery into hand painting has enhanced the range of designing and productivity. Variety of designs was created through the use of CAD technology employing design tools which aided creativity and made the process more efficient. 
of Bijapur, Dharwad, Belgaum and Jamakhandi districts. As an art form, it speaks about the people of Karnataka; their traditions, customs and professions. Its delicate rendition is an outcome of the honest, zealous and innate desire of 'mankind' to practice the beautiful stitches on the articles of everyday use. The motifs used in Kasuti embroidery ranged from mythological and architectural to the beautiful flora and fauna, i.e. gopuras, palanquine, chariot, shiva-linga, bull (Nandi), tiger, lamp stand, crown of Shiva (ShivanaBasinga), swastika, sun, suryamukhi, conchshell, asanas, Rama's cradle, snake (Naga devta), elephant, horse, tulsivrindavan, Hanuman etc. Today kasuti embroidery can be done on any type of fabric. It is done on curtains, cushion covers and many other household articles of hand woven cloth. Stitches in kasuti are always vertical, horizontal and diagonal. The main speciality of this embroidery is that the design is never traced on the material to be embroidered and the embroidery starts without knotting thread but with a tiny back stitch. The stitches are simple, minute, intricate and pretty. Kasuti is always done by counting the threads. The four types of stitches are Gavanti (a double running stitch), "Negi" (a simple running stitch), "Murgi" (a zig-zag stitch) and a cross stitchmenthi (Pandit, 1976)

Due to modernization and changing fashion scenario, demands for new textile designs are increasing day by day (Rai, 2002). New studies emphasized that in the present context of globalization and rapid technology transformation handloom sector is beset with many challenges and the handloom products are being replicated on power looms at much lower cost. Hence, for strengthening this sector product diversification and creating market demand is utmost essential.

Fabric painting can create embroidery like effect on any fabric with the right fabric paint and applicators. Fabric painting gives fabulous surface decoration in lesser time as compared to embroidery. This is also an age-old tradition in India. Today, the usage of fabric painting has revolutionized to such an extent that it is a popular homemade handcraft. It is the lively expression of fabrics. Fabric painting can be carved at a very affordable price with simple techniques and procedures (Devi et al., 2017).

Painting in ancient India was a favourite mode of expression of art. There are innumerable references to painting in the contemporary literature that the art of painting has reached the highest degree of excellence both from the technical and aesthetic point of view.

In an era of time stress, there is a need to explore the possibility of transformation of embroidery designs for fabric painting. The people engaged in the activity of fabric embellishment, will find fabric painting as more convenient and less time-consuming resulting in more earning. Use of traditional embroidery designs for transformation into fabric painting will help in the revival of traditional embroidery and give it a new look as per trend. Keeping these facts in mind a study with the objective of creating designs from selected motifs of Kasuti embroidery for fabric painting was conducted.

\section{Materials and Methods}

\section{Technical plan}

The methods, techniques, tools and procedures adopted for the present investigation have been categorised under following steps to achieve the planned objectives.

\section{Collection of motifs}

Motifs of kasuti embroidery were collected from secondary sources like books, magazines, journals and internet. A total of fifty motifs were collected. The collected motifs were categorized in three categories as 
geometrical, floral, and animal and bird motifs. The categorized motifs were screened into thirty motifs by advisory committee keeping in mind their suitability for fabric painting on selected articles. These three categories included ten motifs each. Thus, a total of thirty motifs were finalized for further research work.

The selected motifs were scanned to convert them from print version to digital format and edited with the help of CorelDraw software. The proportion of motifs was changed to make them suitable for hand painting on textile articles.

\section{Selection of motifs}

Thirty motifs were got assessed by experts with the help of developed preferential index. The experts were asked to give their preferences for each motif separately in different categories for its suitability to hand painting. Their preferences were taken on three-point continuum scale as most preferred, preferred and least preferred. The weighted mean score of each motif was calculated to give ranks in different categories. A total of fifteen motifs including five top ranked motifs from each category i.e. geometrical, floral and animal \& bird motifs were selected to create designs.

\section{Selection of article}

For selection of article to be developed for application of adapted motifs of kasuti embroidery through hand painting technique, a list of textile articles under three broad heads i.e. apparel, accessories and utility articles and home textiles was prepared and sorted with the help of advisory committee members. The articles were selected on the basis of their weighted mean score according to expert's choices. The most preferred article i.e. jacket was selected for product development and application of kasuti embroidery motifs through hand painting technique.

\section{Creation and selection of designs}

Fifteen selected motifs i.e. five top ranked motifs from each category were used to develop designs. Designs were created on the basis of their suitability for fabric painting on jacket with the help of CorelDraw using graph of $2.0 \mathrm{~mm}$ size. Each motif was converted into three designs. Hence, a total of forty-five designs were created. The created designs were got assessed by experts and three top ranked designs were each selected for preparation of design placements on jacket.

\section{Preparation of design placements and their selection}

Three top ranked designs each were used to prepare design placements on jacket. Three placements of each design were made on the article with the help of Corel DRAW. These placements were got assessed by the experts and top ranked placement of each design was selected for hand painting.

\section{Assessment of developed articles}

Consumer acceptability of the developed hand painted jackets were assessed using selfstructured evaluation Performa.

\section{Results and Discussion}

Kasuti embroidery motifs were collected, screened and categorized as geometrical, floral and animal and bird motifs, including ten motifs each. Top ranked five motifs in each category were selected by experts for further research work. A total of forty-five designs were created using fifteen selected motifs, with the help of CorelDraw software. Top ranked three designs were selected for jacket by experts, using a preferential choice index. 
Preferences of experts for design placements on selected articles

Three placements of each selected design were made on front, back of jacket. A total of nine placements were prepared and assessed by experts. The nine placements i.e. three of each selected design are presented in plate I.

Preferences of experts for design placements on jacket

The data envisaged that highly preferred placement of design number 5 was placement III which got $\mathrm{I}^{\text {st }}$ rank with 2.85 WMS. Placement II of design number 5 was preferred placement and got II $^{\text {nd }}$ rank with 2.4 WMS followed by placement I with 2.1 WMS and got III $^{\text {rd }}$ rank. Highly preferred placement of design number 11 was placement I which got $\mathrm{I}^{\text {st }}$ rank with $2.70 \mathrm{WMS}$.

Placement II of design number 11 was preferred placement and got II $^{\text {nd }}$ rank with 2.45 WMS followed by placement III with 1.75 WMS and got $\mathrm{III}^{\text {rd }}$ rank. Placement II of design number 16 was highly preferred with 2.6 WMS and got I ${ }^{\text {st }}$ rank. Placement III of design number 16 was preferred placement and got $\mathrm{II}^{\text {nd }}$ rank with $2.3 \mathrm{WMS}$ followed by placement I with 2.2 WMS and got III $^{\text {rd }}$ rank. Top ranked placement of each design was selected for application on jacket (Table 1).

Thus, placement III of design number 5, placement I of design number 11 and placement II of design number 16 were top ranked and highly preferred placements. These were selected for application on jacket.

Assessment of developed articles for consumer acceptability on various parameters

The developed articles were assessed by sixty consumers for their acceptability level on various parameters. The data revealed that painted jackets with design number 11 and 16 were assessed highly acceptable by consumers on all the four parameters i.e. design placement (2.73), created design (2.7), color way (2.63) and technique (2.5) of design number 11 and design placement (2.66), technique (2.63), created design (2.5) and colour way (2.36) of design number 16. Design number 5 of painted jacket was assessed highly acceptable for its design placement (2.46), created design (2.43), technique (2.4) and (2.38) colour way (Table 2).

Table.1 Preferences of experts for design placements on jacket

\begin{tabular}{|c|c|c|c|c|c|c|}
\hline Design number & \multicolumn{2}{|c|}{ Placement I } & \multicolumn{2}{|c|}{ Placement II } & \multicolumn{2}{|c|}{ Placement III } \\
\hline & WMS & Rank & WMS & Rank & WMS & Rank \\
& $(\mathbf{n = 2 0})$ & & $\begin{array}{c}(\mathbf{n = 2 0}) \\
(\mathbf{n = 2 0})\end{array}$ & \\
\hline $\mathbf{5}$ & 2.1 & III & 2.4 & II & 2.85 & I \\
\hline 11 & 2.7 & I & 2.45 & II & 1.75 & III \\
\hline 16 & 2.2 & III & 2.6 & I & 2.3 & II \\
\hline
\end{tabular}

WMS-Weighted Mean Score, Highly Preferred 2.34-3.00, Preferred 1.67-2.33, Least Preferred 1.00-1.66 
Table.2 Assessment of developed articles for consumers acceptability on various parameters

\begin{tabular}{|l|c|c|c|c|c|}
\hline $\begin{array}{l}\text { Developed selected } \\
\text { articles }\end{array}$ (Design & $\begin{array}{c}\text { Created } \\
\text { designs } \\
\text { (Wumbers) }\end{array}$ & $\begin{array}{c}\text { Design } \\
\text { placements } \\
\text { (WMS) }\end{array}$ & $\begin{array}{c}\text { Colour } \\
\text { Ways } \\
\text { (WMS) }\end{array}$ & $\begin{array}{c}\text { Techniques } \\
\text { (WMS) }\end{array}$ & $\begin{array}{c}\text { Average } \\
\text { score }\end{array}$ \\
\hline Painted jacket (5) & 2.43 & 2.46 & 2.38 & 2.4 & 2.41 \\
Painted jacket (11) & 2.7 & 2.73 & 2.63 & 2.5 & 2.64 \\
Painted jacket (16) & 2.5 & 2.66 & 2.36 & 2.63 & 2.53 \\
\hline Average Score & 2.54 & 2.61 & 2.45 & 2.51 & 2.52 \\
\hline
\end{tabular}

Table.3 Assessment of developed jackets as per overall appearance

\begin{tabular}{|l|c|c|}
\hline \multicolumn{3}{|c}{ Overall Appearance } \\
Developed articles & WMS & Rank \\
\hline (Design Numbers) & 2.53 & III \\
\hline Painted jacket (5) & $\mathbf{2 . 7 3}$ & I \\
\hline Painted jacket (11) & 2.70 & II \\
\hline Painted jacket (16) & & \\
\hline
\end{tabular}

Table.4 Opinion of the consumers regarding adaptation of kasuti embroidery motifs for hand painted $(n=60)$ 
Plate.1 Design placements of selected designs on jackets

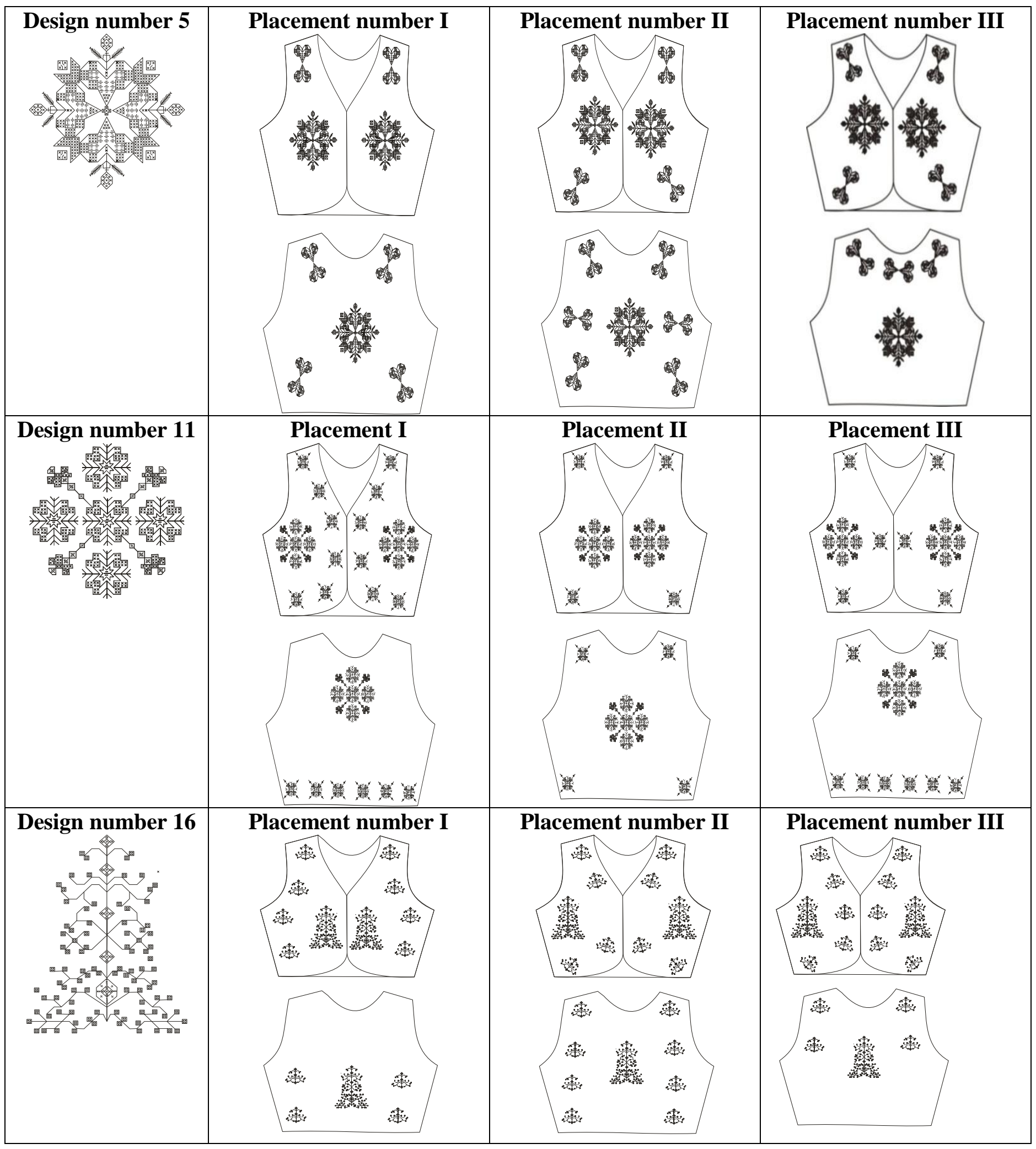


Developed jackets with hand painting technique

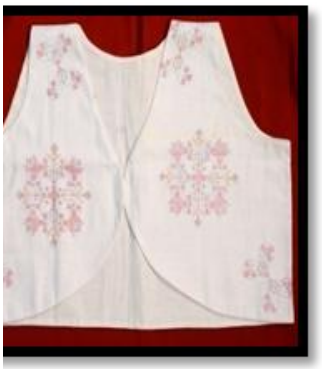

Front

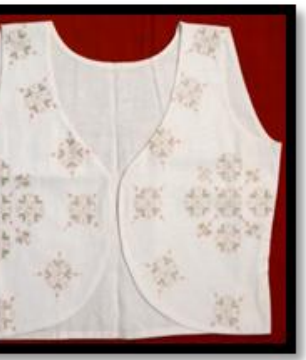

Front

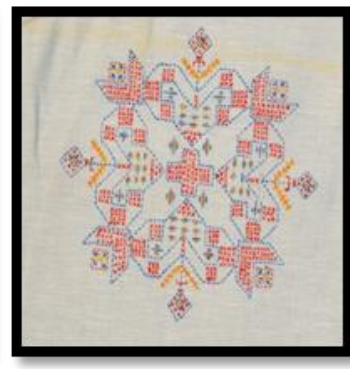

Design

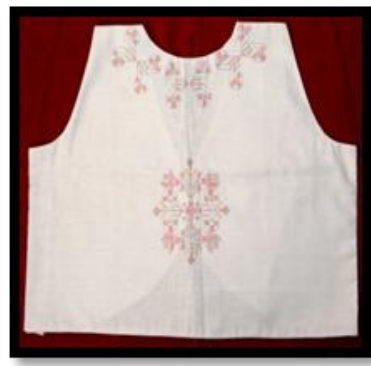

Back

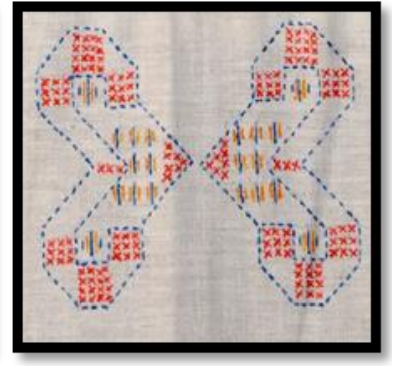

Filler

Design number 5

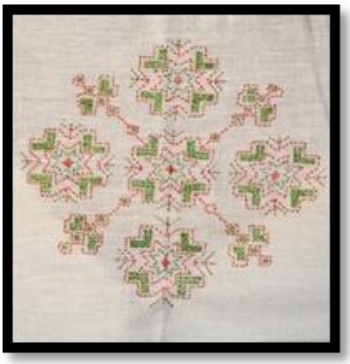

Design

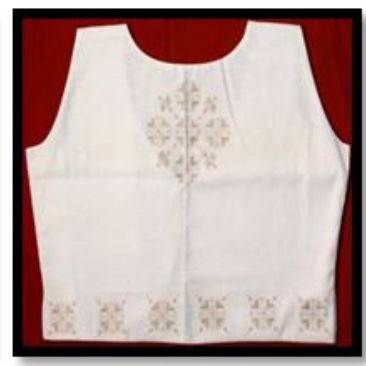

Back

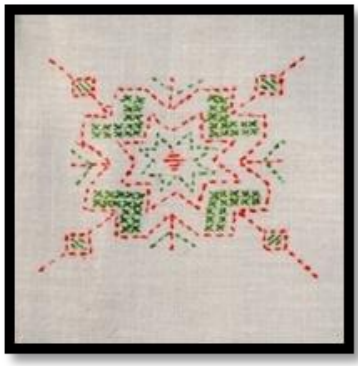

Filler

Design number 11

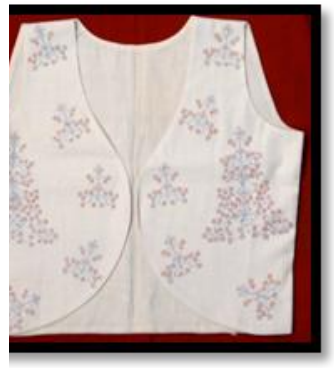

Front

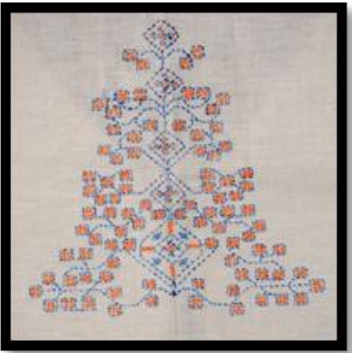

Design

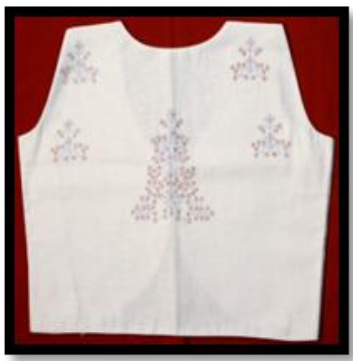

Back

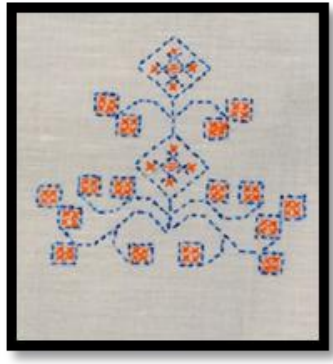

Filler

Design number 16

Assessment of developed articles as per overall appearance

The data presented, elucidated that design number 11 of painted jacket got I ${ }^{\text {st }}$ rank with 2.73 score followed by design number 16 with 2.70 score got II $^{\text {nd }}$ rank with painted jacket of design number 5 got III $^{\text {rd }}$ rank with 2.53 score as per overall appearance (Table $3)$.
Thus, it is inferred that in terms of overall appearance, all the jackets were assessed as highly appealing.

Opinion of the consumers regarding adaptation of kasuti embroidery motifs for hand painting

The study envisaged that foremost opinion of consumers regarding adaptation of kasuti 
embroidery for fabric painting was that 'fabric painting maintains the beauty of kasuti embroidery' with 2.70 WMS got $\mathrm{I}^{\text {st }}$ rank, followed by the opinion that 'effect kasuti embroidery can be effectively replicated with fabric painting' with 2.63 WMS got II ${ }^{\text {nd }}$ rank, 'selected technique is easy in execution with 2.53 WMS got III' ${ }^{\text {rd }}$ rank, 'selected technique is as per latest consumer's demand with 2.5 WMS got $\mathrm{IV}^{\text {th }}$ rank and 'fabric painting is time saving and cost effective surface embellishment technique' with 2.43 WMS got $\mathrm{V}^{\text {th }}$ rank. Thus, consumers had high opinion regarding adaptation of kasuti embroidery for hand painting as they strongly opined that hand painting is time saving and costeffective surface embellishment technique as per latest consumer's demand. It was easy in execution and has effectively replicated the effect of kasuti embroidery to maintain its beauty with WMS ranging between 2.43 to 2.70 (Table 4).

Adaptation of traditional kasuti embroidery motifs for hand painting enhanced the possibility of creativity. Developed articles were highly acceptable by respondents in terms of created designs, design placements, colour ways, technique, overall appearance and cost. Respondents had high opinion about developed articles. Transformation of innovative designs of kasuti embroidery into hand painting has enhanced the range of designing and productivity. Variety of designs can be created through the use of CAD technology employing design tools which aid creativity and make the process more efficient.

\section{Recommendations}

Developed kasuti embroidery hand painted designs can be used for variety of textile, apparel and household articles. The findings of this research can be disseminated to the persons who are working towards revival of traditional embroideries. This activity can be taken up by women entrepreneurs to start a small-scale business as fabric painting is an innovative, economical and time saving surface embellishment technique.

\section{References}

Bennur, S. and Gavai, L. 2015. Regional traditional Indian embroidery "Kasuti" key success factors to reach the international markets. Journal of Textile Science \& Engineering. 5: 3.

Devi, S., Punia, P., Pruthi, N. and Sisodia, N. 2017. Transformation of kantha traditional embroidery: as fabric painting. Indian Journal of Traditional Knowledge 16(4): 720-725.

Naik, S. D. and Vastrad, V. J. 2008. Protection and revival of traditional hand embroidery, Kasuti by Automation. Indian Journal of Traditional Knowledge. 7(1): 197-203.

Pandit, S. 1976. Indian Embroidery- Its variegated charms. Jaymudra, Laxmi Estate, Bahuchargi Road, Baroda: 1820.

Rai, I. 2002. Problems and prospects in the $21^{\text {st }}$ century. Books treasure, Jodhpur. Pp: 132-133.

\section{How to cite this article:}

Renu, Nisha Arya, N. Chauhan and Suman Sodhi. 2018. Transformation of Kasuti Embroidery Motifs for Hand Painting. Int.J.Curr.Microbiol.App.Sci. 7(04): 1010-1017. doi: https://doi.org/10.20546/ijcmas.2018.704.110 